Document downloaded from:

http://hdl.handle.net/10251/161383

This paper must be cited as:

Quiles-Carrillo, L.; Montanes, N.; Fombuena, V.; Balart, R.; Torres-Giner, S. (2020).

Enhancement of the processing window and performance of polyamide 1010/bio-based high-density polyethylene blends by melt mixing with natural additives. Polymer International. 69(1):61-71. https://doi.org/10.1002/pi.5919

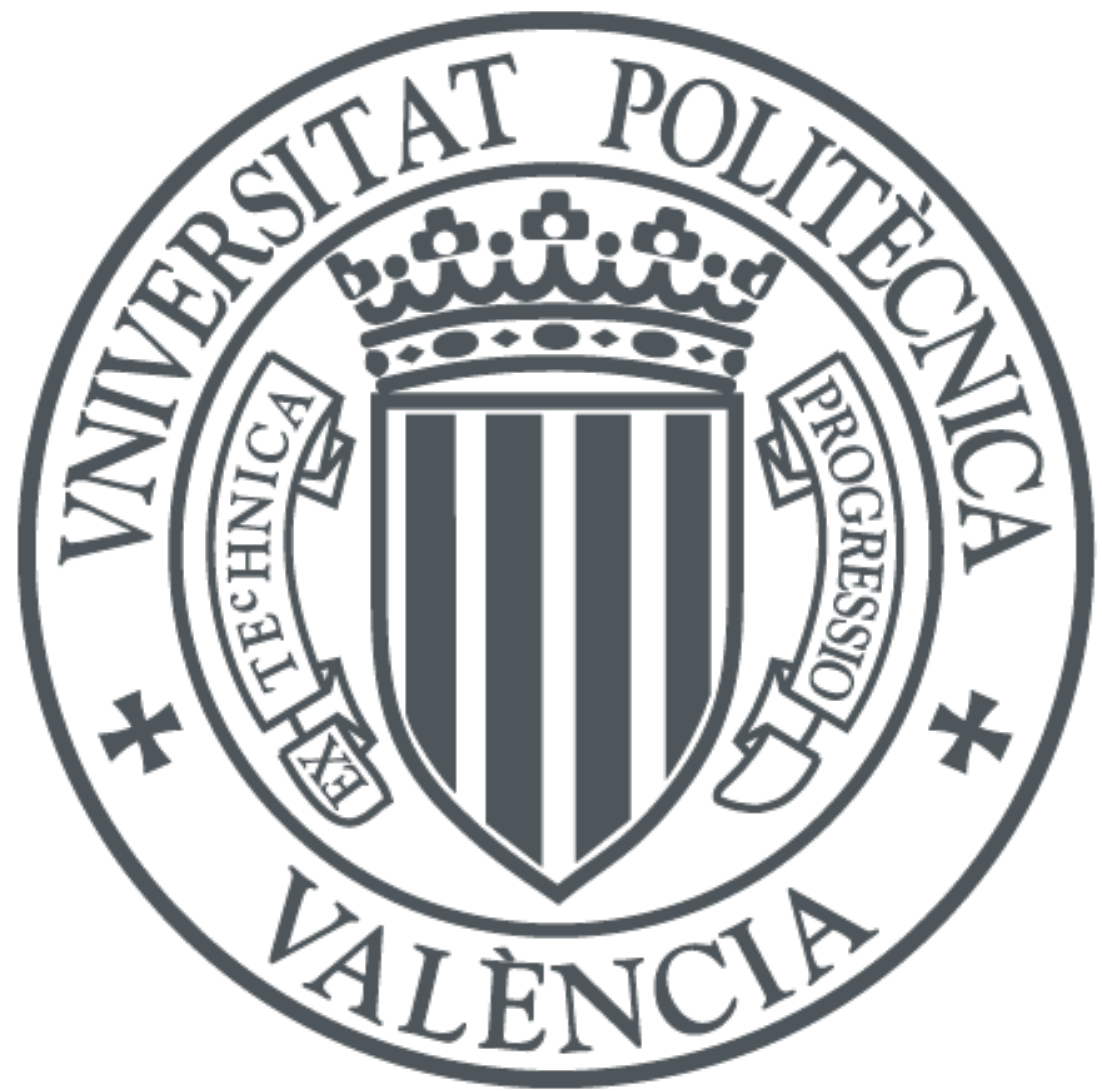

The final publication is available at

https://doi.org/10.1002/pi.5919

Copyright John Wiley \& Sons

Additional Information 


\title{
Enhancement of the processing window and performance of polyamide 1010/bio-based high-density polyethylene blends by melt mixing with natural additives
}

\author{
L. Quiles-Carrillo ${ }^{(1)^{*}}$, N. Montanes (1), V. Fombuena (1), R. Balart (1), S. \\ Torres-Giner ${ }^{(2)}$ \\ 1 Technological Institute of Materials (ITM), Universitat Politècnica de València \\ (UPV), Plaza Ferrándiz y Carbonell 1, 03801 Alcoy, Spain; \\ 2 Novel Materials and Nanotechnology Group, Institute of Agrochemistry and Food \\ Technology (IATA), Spanish National Research Council (CSIC), Calle Catedrático \\ Agustín Escardino Benlloch 7, 46980 Paterna, Spain. \\ *Corresponding author: L. Quiles-Carrillo (luiquic1@epsa.upv.es)
}

\begin{abstract}
This work reports the enhancement of the processing window and the mechanical and thermal properties of biopolymer blends of polyamide 1010 (PA1010) and bio-based high-density polyethylene (bio-HDPE) at 70/30 (wt/wt) achieved by means of natural additives. The overall performance of the binary blend melt-mixed without additives was poor due to both the relatively low thermal stability of bio-HDPE at the processing temperatures of PA1010, that is, $210-240{ }^{\circ} \mathrm{C}$, and the lack or poor miscibility between the two biopolymers. Gallic acid (GA), a natural phenolic compound, was added at 0.8 parts per hundred resin (phr) of biopolymer blend to enhance the thermal stability of the green polyolefin and therefore enlarge the processing window of the binary blend. Maleinized linseed oil (MLO), a multifunctionalized vegetable oil, was then incorporated at $5 \mathrm{phr}$ to compatibilize the biopolymers and its performance was also compared with that of a conventional petroleum-derived copolymer, namely, poly(ethylene-co-acrylic acid) (PE-co-AA). The
\end{abstract}


resultant biopolymer blends showed a remarkable enhancement in the thermal stability and also improved toughness when both natural additives were combined. This work can potentially serve as a sound base study for the mechanical recycling of similar blends based on bio-based but non-biodegradable polymers.

Keywords: PA1010; Green polyethylene; Thermal stability; Mechanical properties; Secondary Recycling 


\section{INTRODUCTION}

In the last years, several aliphatic polyamides (PAs) have been totally or partially obtained from bio-based building blocks. ${ }^{1}$ In this regard, polyamide 1010 (PA1010) can be produced using 1,10-decametylene diamine (DMDA) and sebacic acid, which can be synthesized from a natural source, that is, castor oil, which certainly plays a key role in bio-based polyamides (bio-Pas). ${ }^{2}$ PA1010 is fully bio-based and it is especially useful in engineering applications requiring flexibility, heat resistance, and low extraction.3,4 Aligned with the principles of the Circular Economy, the possibility of PAs to be recycled has also raised a great interest..$^{5-7}$ Chemical or tertiary recycling of PAs by depolymerization to obtain the original monomers is, however, still not fully technological and economically feasible. ${ }^{8}$ Alternatively, the environment benefits of plastic incineration are questionable. For these reasons, mechanical or secondary recycling is nowadays regarded as the most sustainable alternative, with excellent balance between technical viability, costs, and environmental benefits. ${ }^{9}$

Some of the drawbacks related to mechanical recycling are the contamination with other polymers, thermal degradation, and the poor (or lack of) miscibility, which result in a remarkable decrease in mechanical properties. ${ }^{10}$ It is worthy to note the increasing use of PA/polyolefin laminates, such as those based on high-density polyethylene (HDPE), in the packaging industry. ${ }^{11}$ The selection of the optimal processing window for the mechanical recycling of PA/HDPE blends is critical since the processing temperature of the $\mathrm{PA}$ is higher than the onset degradation temperature of HDPE. Therefore, the polyolefin may undergo thermal degradation during melt processing at temperatures in the $220-240{ }^{\circ} \mathrm{C}$ range, or due to the presence of light, heat, or chemicals.12 Moreover, since both polymers in article are immiscible, their melt-reprocessed blends show phase separation and poor mechanical properties. ${ }^{13,14}$

The use of antioxidants can improve the stability and enlarge the processing window of polyolefins and their blends. Nevertheless, bearing in mind the strong environmental concern related to plastic additives, the use of natural antioxidants is 
currently preferred over petroleum-derived antioxidants. ${ }^{15}$ Indeed, natural antioxidants can successfully provide similar stabilizing properties in polymers than synthetic phenolic-type antioxidants. ${ }^{16},{ }^{17}$ In this sense, gallic acid (GA) is one of the most interesting natural antioxidants, and it can be found in a variety of fruits and vegetables such as grapes, green tea, tea leaves, tomatoes and carob pods. ${ }^{18,}{ }^{19}$ Spain is the main producer of carob, followed by Italy, Portugal, and Morocco. ${ }^{20}$ Moreover, GA can be effectively obtained from carob pods microwave-assisted extraction. ${ }^{21}$

The addition of copolymers to polymer blends can increase the morphological stability and interfacial adhesion of polymer blends to overcome or minimize the effects of immiscibility. ${ }^{22}$ For instance, poly(ethylene-co-glycidyl methacrylate) polymers yield interesting compatibilization properties due to the reactivity of the glycidyl methacrylate group, ${ }^{23}, 24$ thus leading to blends with enhanced properties. ${ }^{25}$ From a more sustainable point of view, the use of multi-functionalized vegetable oil derivatives represents an environmentally friendly solution to achieve compatibilization. ${ }^{26,}{ }^{27}$ To this end, vegetable oils are subjected to chemical modifications, such as acrylation, ${ }^{28}$ epoxidation $^{29} 29,30$ or maleinization ${ }^{31,}{ }^{32}$. In this regard, maleinized linseed oil (MLO) has shown interesting results as a compatibilizer for polymer blends. ${ }^{33-37}$

The aim of this work is to improve the thermal stability and the mechanical and thermomechanical properties of binary blends made of PA1010 and bio-based high-density polyethylene (bio-HDPE) by means of natural additives. On the one hand, the use of GA was intended to extend the processing window of bio-HDPE to avoid degradation during processing of the biopolymer blends. On the other, MLO was added to increase the chemical interactions between the two immiscible biopolymers.

\section{EXPERIMENTAL}

\subsection{Materials}

PA1010, was supplied as NP-PA1010-201, in a pellet forms by NaturePlast (Ifs, France). This grade is a long chain PA, fully bio-based and characterized by a medium viscosity. 
It is an injection-grade homopolyamide with a density of $1.05 \mathrm{~g} / \mathrm{cm}^{3}$ and a viscosity number (VN) of $160 \mathrm{~cm}^{3} / \mathrm{g}$. Bio-HDPE, commercial grade of HDPE SHA7260, was supplied by Braskem (São Paulo, Brazil). This green polyethylene has a density of $0.955 \mathrm{~g} / \mathrm{cm}^{3}$ and a melt flow index (MFI) of $20 \mathrm{~g} / 10 \mathrm{~min}$, measured with a load of $2.16 \mathrm{~kg}$ at a temperature of $190^{\circ} \mathrm{C}$.

GA, with commercial reference $\mathrm{G} 7384$ and $170.12 \mathrm{~g} / \mathrm{mol}$ was supplied in powder form by Sigma-Aldrich S.A. (Madrid, Spain). This is a water-soluble phenolic acid obtained from grapes and the leaves of different plants. MLO was obtained from Vandeputte (Mouscron, Belgium) as VEOMER LIN. This has a viscosity of $1,000 \mathrm{cP}\left(20^{\circ} \mathrm{C}\right)$ and an acid value of 105-130 mg KOH/g. Poly(ethylene-co-acrylic acid) (PE-co-AA), with CAS Number 9010-77-9, an acrylic acid content of $20 \mathrm{wt} \%$, and density of $0.96 \mathrm{~g} / \mathrm{cm}^{3}$ at $25{ }^{\circ} \mathrm{C}$ was supplied by Sigma-Aldrich S.A. (Madrid, Spain). Scheme 1 summarizes the chemical structures of all these materials. All materials were used as received without any purification process.

\subsection{Manufacturing of blends}

Prior to processing, PA1010 and Bio-HDPE were subjected to a drying process at $60{ }^{\circ} \mathrm{C}$ for $48 \mathrm{~h}$ in a dehumidifying dryer MDEO to remove any residual moisture. The extrusion was carried out in a co-rotating twin-screw extruder manufactured by Construcciones Mecánicas Dupra, S.L. (Alicante, Spain). The rotating speed of the screws was relatively low to enhance good mixing and was stablished at $20 \mathrm{rpm}$. The temperature profile was adjusted as follows: 220 (hopper)-230-235-240 (die) ${ }^{\circ} \mathrm{C}$. The screws had a diameter of $25 \mathrm{~mm}$ with a L/D ratio of 24 (length to diameter ratio). Table 1 summarizes the composition of the blends.

The compounded pellets obtained after extrusion were, thereafter, shaped into standard samples by injection molding using a Meteor 270/75 from Mateu \& Solé (Barcelona, Spain), using a temperature profile of $210^{\circ} \mathrm{C}$ (hopper), $220^{\circ} \mathrm{C}, 230^{\circ} \mathrm{C}$, and $240{ }^{\circ} \mathrm{C}$ (injection nozzle). A clamping force of 75 tons was applied while the cavity 
filling and cooling times were set to 1 and $10 \mathrm{~s}$, respectively. Different standard samples with an average thickness of $4 \mathrm{~mm}$ were obtained for further characterization.

\subsection{Mechanical characterization}

Characterization of the tensile properties of PA1010/bio-HDPE blends was carried out in a universal test machine Elib 50 from S.A.E. Ibertest (Madrid, Spain) using injection-molded dog bone-shaped samples according to ISO 527-1:2012. A $5 \mathrm{kN}$ load cell was used for all tensile tests while the cross-head speed was set to $10 \mathrm{~mm} / \mathrm{min}$. Shore hardness values of the samples were collected using a 676-D durometer from J. Bot Instruments (Barcelona, Spain), using the D-scale. Shore D measurements were conducted on injection-molded samples sizing $80 \times 10 \times 4 \mathrm{~mm}^{3}$, according to ISO 868:2003. Toughness was also assessed on rectangular samples (80x10x4 $\mathrm{mm}^{3}$ ) by measuring the impact strength on a 6-J Charpy pendulum from Metrotec S.A. (San Sebastián, Spain) on notched samples with a "V" type notch (0.25 mm radius, as recommended by ISO 179-1:2010. All tests were performed at room temperature and, at least, 6 samples of each material were tested, and the corresponding mechanical parameters obtained from each test were averaged.

\subsection{Morphology characterization}

Due to the immiscibility of Bio-HDPE and PA1010, the morphology of the fractured surfaces obtained after impact tests, was observed by field emission scanning electron microscopy (FESEM) in a ZEISS ULTRA 55 from Oxford Instruments (Abingdon, United Kingdom) working at an acceleration voltage of $2 \mathrm{kV}$. As these polymer blends were not electrical conducting materials, the surfaces were subjected to a sputtering process to deposit an ultrathin gold-palladium alloy using an EMITECH sputter coating SC7620 supplied by Quorum Technologies, Ltd. (East Sussex, UK).

\subsection{Infrared spectroscopy}


Chemical analysis was performed using attenuated total reflection-Fourier transform infrared (ATR-FTIR) spectroscopy. Spectra were recorded with a Vector 22 from Bruker S.A. (Madrid, Spain) coupling a PIKE MIRacle ${ }^{\mathrm{TM}}$ ATR accessory from PIKE Technologies (Madison, WI, USA). Ten scans were averaged from $4000 \mathrm{~cm}^{-1}$ to $500 \mathrm{~cm}^{-1}$ at a resolution of $4 \mathrm{~cm}^{-1}$.

\subsection{Thermal characterization}

Thermal characterization of PA1010/bio-HDPE blends was studied by differential scanning calorimetry (DSC) in a Mettler-Toledo 821 calorimeter (Schwerzenbach, Switzerland). A sample weight comprised between 5-7 mg was subjected to a dynamic thermal program divided in three different stages: initially, a first heating cycle from $30^{\circ} \mathrm{C}$ to $220^{\circ} \mathrm{C}$ was, followed by controlled cooling to $-50{ }^{\circ} \mathrm{C}$. Finally, a second heating stage from $-50^{\circ} \mathrm{C}$ up to $350^{\circ} \mathrm{C}$ was scheduled. The heating and cooling rates were set to $10{ }^{\circ} \mathrm{C} / \mathrm{min}$. All tests were run in nitrogen atmosphere with a flow of $66 \mathrm{~mL} / \mathrm{min}$ using standard sealed aluminum pans with a total volume of $40 \mu \mathrm{L}$. The degree of crystallinity $\left(\chi_{c}\right)$ (in percentage, \%) was calculated for both semicrystalline PA1010 and bio-HDPE polymers following Equation 1:

$$
\chi_{C}=\left[\frac{\Delta H_{m}}{\Delta H_{m}^{0} \cdot(1-w)}\right] \cdot 100 \quad \text { Equation } 1
$$

In the previous equation, $\Delta H_{m}$ corresponds to the melt crystallization enthalpy obtained after integration of the corresponding endothermic peak of bio-HDPE or PA1010. $\Delta H_{m}{ }^{o}(\mathrm{~J} / \mathrm{g})$ stands for the melt enthalpy of a theoretically fully crystalline polymer. This value is $293.0 \mathrm{~J} / \mathrm{g}$ for bio-HDPE and $244 \mathrm{~J} / \mathrm{g}$ for PA1010.38 Finally, (1- $w$ ) represents the weight fraction the polymer whose crystallinity is being calculated, with their corresponding $\Delta H_{m}$ and $\Delta H_{m}{ }^{o}$ values.

Thermal stability in more aggressive conditions (degradation/decomposition) was studied by thermogravimetry (TGA) in a Mettler-Toledo TGA/SDTA 851 
thermobalance (Schwerzenbach, Switzerland). The sample weight was also set to 5$7 \mathrm{mg}$ to enhance reproducibility. Samples were placed into standard alumina crucibles of $70 \mu \mathrm{L}$ and then, subjected to a dynamic heating cycle from 30 up to $700{ }^{\circ} \mathrm{C}$. The selected heating rate was $20^{\circ} \mathrm{C} / \mathrm{min}$. All TGA tests were conducted in air atmosphere.

\subsection{Thermomechanical characterization}

Dynamical mechanical properties as a function of temperature were obtained in a DMA1 dynamic analyzer from Mettler-Toledo (Schwerzenbach, Switzerland), working in flexural conditions (single cantilever). The sample size for these tests were rectangular shapes with dimensions $20 \times 6 \times 2.7 \mathrm{~mm}^{3}$. A dynamic temperature sweep was scheduled to evaluate dynamic-mechanical properties in terms of increasing temperature from $-160{ }^{\circ} \mathrm{C}$ up to $150{ }^{\circ} \mathrm{C}$ at a constant heating rate of $2{ }^{\circ} \mathrm{C} / \mathrm{min}$. The frequency was set to $1 \mathrm{~Hz}$ while the maximum allowed deflection was $10 \mu \mathrm{m}$.

In addition to DMTA characterization, the dimensional stability of PA1010/bioHDPE blends was estimated by thermomechanical analysis (TMA) in a Q-400 thermoanalyzer from TA Instruments (Newcastle, DE, USA). Rectangular samples with dimensions $10 \times 10 \times 4 \mathrm{~mm}^{3}$ were subjected to a dynamic temperature ramp from $-150{ }^{\circ} \mathrm{C}$ up to $150^{\circ} \mathrm{C}$ using a constant heating rate of $3{ }^{\circ} \mathrm{C} / \mathrm{min}$ and a constant applied load of $20 \mathrm{mN}$.

\section{RESULTS ANS DISCUSION}

\subsection{Mechanical characterization}

Table 2 shows the mechanical properties of the PA1010/bio-HDPE blends. In particular, the values of the tensile modulus, maximum tensile strength, elongation at break, hardness and impact strength are displayed. Neat PA1010 showed values of tensile modulus and strength of $639.2 \mathrm{MPa}$ and $48.6 \mathrm{MPa}$, respectively, with a high elongation at break of $515.8 \%$. This tensile strength is typical of engineering plastics. 39 One can observe that neat PA1010 is not a stiff 
material but it shows a high toughness. The addition of $30 \mathrm{wt} \%$ of bio-HDPE to PA1010 resulted in a lower tensile modulus, down to $300 \mathrm{MPa}$, increasing the material's ductility. Nevertheless, it is worthy to note the decrease observed in tensile strength, down to $26.9 \mathrm{MPa}$, which represents almost half the value of neat PA1010. This decrease is directly related to the poor miscibility between both biopolymers in the blend. In addition, a dramatic decrease in elongation at break from $515.8 \%$ to $72.8 \%$ was observed. In this sense, Scaffaro et al. ${ }^{40}$ reported similar results in polyamide 6 (PA6)/HDPE blends. It was indicated that the decrease in elongation at break was more pronounced at high HDPE contents in the blend. For instance, the $\mathrm{HDPE}_{25} / \mathrm{PA}_{75}$ was reduced down to $4.7 \%$, while the effect of the addition of 25 wt\% HDPE on the elongation at break of PA6 was not significant, resulting in a final elongation at break of $20 \%$.

The loss in mechanical properties is highly affected by the poor miscibility between both materials. Similar results were shown by Chen et al. ${ }^{41}$ for PA6/HDPE blends. In particular, they demonstrated a dramatic decrease in elongation at break in comparison to neat PA6 and HDPE, which was attributed to the poor interfacial adhesion between the HDPE matrix and the dispersed PA6 phase. In addition to poor miscibility, the here-obtained poor mechanical properties could also be related to somewhat thermal degradation of bio-HDPE during. One can observe that the addition of GA had a positive effect on overall mechanical properties of PA1010/bio-HDPE blend. The tensile strength remained almost constant with a value of 26.1 MPa but the elongation at break was almost doubled. So that, in addition to the antioxidant properties that $0.8 \mathrm{phr}$ GA can provide to the binary blend, a clear positive effect on mechanical properties was attained. In particular, it resulted in a remarkable increase in elongation at break. This could be related to a plasticizing effect or even an improvement related to the thermal stability that GA provides to bio-HDPE during processing. In this regard, Ambrogi et al. $4^{2}$ reported a similar mechanical behavior with some natural antioxidants in PP. In particular, 
it was indicated an increase in elongation at break by using different natural antioxidants, namely, Pycnogenol ${ }^{\circledR}$ from maritime pine bark, carotenoids from tomato oleoresin, and a derivative from Cabernet pomace grape. Accordingly, this observation suggests that the addition of natural antioxidants also produces a slight decrease in both tensile modulus and strength. The presence of antioxidants could also impair crystallinity with the subsequent decrease in tensile modulus and strength. 43 For instance, Jamshidian et al.43 reported that the incorporation of several natural antioxidants such as ascorbyl palmitate (AP) and $\alpha$-tocopherol (AT) exerted a clear plasticization on polylactide (PLA).

The addition of the different compatibilizers also provided some changes in the mechanical properties of the PA1010/bio-HDPE blend. The addition of MLO slightly reduced the tensile modulus and strength by 10\% but increased elongation at break by $5 \%$. In this sense, MLO can successfully provide additional plasticization properties to the blend, thus leading to an improvement in ductile properties. Similar results have been reported in binary systems such as PLA/thermoplastic starch (TPS) blends44 and polybutylene succinate (PBS) composites with almond shell flour (ASF). 45 In both systems, the overall effect of MLO addition was remarkable on the improvement ductility and compatibility between the different components. With regard to PE-co-AA, it provided superior properties to the PA1010/bio-HDPE blend when compared to MLO. The most relevant changes were related to the increase in both tensile strength and elongation at break, which is a clear evidence of the compatibilizing effect that PEco-AA can provide to the binary blend. Halldén et al. ${ }^{46}$ showed very similar results in binary blends of low-density polyethylene (LDPE) and PA6, where the addition of PE-co-AA into the mixture markedly improved the elongation at break. It was also indicated the high efficiency of poly(ethylene-graft-ethylene oxide) (PE-gPEO) as compatibilizer in this binary blend. 
After the addition of bio-HDPE to PA1010, a nearly 4-fold reduction of hardness was observed. This can be related to the intrinsically lower hardness of bio-HDPE than PA1010, being the latter an engineering polymer. The incorporation of the GA and the PE-co-AA did not affect this hardness but the addition of MLO provided lower hardness due to its plasticizing effect. With regard to the overall toughness, estimated by the impact strength, the blend of PA1010 containing 30 wt\% bio-HDPE showed a remarkable decrease in the impact strength from $8.3 \mathrm{~kJ} / \mathrm{m}^{2}$, for neat PA1010, down to $2.8 \mathrm{~kJ} / \mathrm{m}^{2}$, for the PA1010 blend with 30 wt\% bio-HDPE. Impact strength is directly related to material's cohesion and, as expected, PA1010 and bio-HDPE are not miscible, as it will be discussed further. In any case, the plasticizing effect of the natural additive was enough to improved impact strength up to values of $3.7 \mathrm{~kJ} / \mathrm{m}^{2}$. Despite this, the highest impact strength was obtained by the combination of both GA and MLO, showing values of $4.3 \mathrm{~kJ} / \mathrm{m}^{2}$ that are still far from the values of neat PA1010. Despite this, the positive effect of the GA and MLO combination is clearly observed due to the impact strength was improved in comparison with the uncompatibilized PA1010/bio-HDPE blend. Several works have reported that MLO can perform as a bio-based solution to improve toughness in brittle materials such as PLA and its green composites with hazelnut shell flour (HSF). ${ }^{28,} 47$ Furthermore, as one can observe, PE-co-AA compatibilizer also increased both tensile strength and elongation at break, both parameters having a positive effect on the overall material's toughness. Scaffaro et al. ${ }^{\circ 0}$ showed a similar improvement in PA6/LDPE blends.

\subsection{Morphological characterization}

Figure 1 shows the FESEM images of the fracture surfaces of the PA1010/bioHDPE blends from the impact tests. Figures 1a-b correspond to the fracture surfaces of neat PA1010. These micrographs revealed a fracture surface with a very irregular and 
rough appearance, showing the typical cavernous formations of a polymer with a ductile behavior. Figures 1c-d show that the addition of bio-HDPE to the PA1010 matrix resulted in a phenomenon of phase separation. The aforementioned low miscibility between both biopolymers can be clearly seen in the blend sample containing 30 wt\% bio-HDPE, presenting the typical droplet like structure. Bio-HDPE appeared as micro-sized spherical domains or droplets with an average diameter comprised in a wide range from 4 to $17 \mu \mathrm{m}$. This morphology is responsible for the decrease observed in tensile strength, elongation at break and impact strength, due to the lack of material's cohesion. The two components of the blend were then strongly incompatible and the blend showed a biphasic structure with large voids and poor adhesion between the two phases. ${ }^{48}$ In this sense, Utraki et al. ${ }^{49}$ reported that the absence of a co-continuous phase morphology is representative for immiscibility. The presence of small gaps of $1-3 \mu \mathrm{m}$ surrounding the polyolefin domains supported the poor material's cohesion that, in turn, was responsible for the decrease in both elongation at break and tensile strength. The addition of GA to the blend system resulted in a better homogenization of the particle size but the immiscible droplets of bio-HDPE were still clearly discerned in the PA1010 matrix so that its effect on morphology was relatively low. Although plasticization was pointed out during the mechanical properties, this effect was not detectable during the morphological analysis. With respect to the effect of the two compatibilizers, one can observe that both MLO and PE-co-AA modified the morphology of the biopolymer blends. Figures 1e-f show the morphology of the fracture surfaces of the blend processed with MLO as compatibilizer. It should be noted that the droplets lost their spherical shape, forming stretched domains along the PA1010 matrix. It is also possible to observe a slight improvement in the miscibility in the mixture since the gaps were noticeably reduced. In this sense, the incorporation of the MLO generates a clear plasticization effect in the bio-HDPE. In a previous work, this plasticization phenomenon has already been observed in bio-HDPE/PLA blends with the typical droplet-like structure related to 
phase separation. In this study, the addition of the modified vegetable oil shows in a clear way a change in the droplet shape from spherical shapes to elliptical (stretched) shapes which give evidences of plasticization. $5^{\circ}$ Other authors have reported the good plasticizing capacity of multi-functionalized vegetable oils in polymers. ${ }^{29,}{ }^{51,}{ }^{2}$ GarciaCampos et al.53 also reported that the addition of acrylated and epoxidized vegetable oils offered quite good phase continuity as well as important evidences of plastic deformation after the impact test. Although the effect of MLO was clear and it provided the highest impact strength of all the developed materials, as observed during the mechanical analysis, the addition of PE-co-AA as compatibilizer also showed a positive effect on the overall miscibility with the subsequent increase in both tensile strength and elongation at break. Figures 1i-j gather the morphology of the PA1010/bio-HDPE blend compatibilized with PE-co-AA. As it can be seen, the mean droplet size was remarkably reduced down to values of $5 \mu \mathrm{m}$ or even lower, which is representative for a good compatibilizing effect. In addition, the gap between the dispersed bio-HDPE droplets almost disappeared. The resultant improved matrix continuity supports the improvement on the mechanical properties related to material's cohesion, that is, tensile strength, elongation at break, and impact strength. Similar to the results reported here, Halldén et al. ${ }^{46}$ demonstrated that an uncompatibilized blend of LDPE with PA6 at 70/30 (wt/wt) results in a droplet like morphology with a sphere size of $21 \mu \mathrm{m}$ while the same blend, containing 4\% PE-co-AA, produces a remarkably reduced size of $0.9 \mu \mathrm{m}$ that were aggregated to larger structures. Therefore, the use of PE-co-AA compatibilizers is able to act as good interfacial adhesion enhancer between the highly immiscible LDPE/PA6 blends. In this regard, our recent research reported on biopolymer blends that the reduction of the gap along the biopolymer-biopolymer interface is an indicator of improved compatibility..$^{50}$ Therefore, the present result suggests that higher coalescence stabilization in the PA1010/bio-HDPE blend was successfully achieved due to the PE-co-AA multi-functionality. This phenomenon can then explain the improved impact strength observed during the impact tests. Similar 
results with other copolymers were previously reported by Wang et al. 54 where PE-gMA was used as a compatibilizer between HDPE and poly(ethylene-co-vinyl alcohol) $(\mathrm{EVOH})$. It was observed that the domain size of EVOH significantly decreased in the HDPE matrix.

\subsection{Chemical characterization}

FTIR was performed in order to ascertain the chemical changes produced in PA1010 after blending with bio-HDPE and the addition of GA and the MLO and (PE-co-AA) compatibilizers. Figure 2 shows the FTIR absorbance spectra of PA1010 and the PA1010/bio-HDPE blends with GA and the different compatibilizers. In the PA1010 spectra one can observe that the main absorption peak was located at $1635 \mathrm{~cm}^{-1}$, which has been assigned to the $\mathrm{C}=\mathrm{O}$ of Amide I in both $\alpha$ - and $\beta$-crystalline phases. ${ }^{38,} 55,56$ The other most intense peak was located at $1535 \mathrm{~cm}^{-1}$, which belongs to the bending vibration of $\mathrm{N}-\mathrm{H}$ in Amide II.55-57 Moreover, the $\mathrm{C}-\mathrm{N}$ stretching vibration of the amide groups $^{38}$ and $\mathrm{C}-\mathrm{H}$ bending vibration in methylene groups appeared on the band $1462 \mathrm{~cm}^{-1} .5^{6}$ The group of bands located in the range $1300-1200 \mathrm{~cm}^{-1}$ can be attributed to the gauche nitrogen-methylene group, that is, the $\mathrm{N}-\mathrm{H}$ and $\mathrm{C}-\mathrm{H}$ twisting. ${ }^{58,} 59$ Finally, the low-intense peaks centered at $1160 \mathrm{~cm}^{-1}$ and $940 \mathrm{~cm}^{-1}$ have been attributed to the skeletal motion and in-plane modes of $\mathrm{CO}-\mathrm{NH}$ bonds, respectively, which are characteristic of amide groups in semi-crystalline polyamides. ${ }^{60}$ After the addition of bio-HDPE, it was observed slight intensity increases of the peaks centered at $1460 \mathrm{~cm}^{-1}$ and $725 \mathrm{~cm}^{-1}$, being those assigned to symmetric stretching vibration of the methylene $\left(\mathrm{CH}_{2}\right)$ groups $^{61}$ and indicating the presence of the green polyolefin in the blend. The incorporation of GA into the blends slightly changed the bands arising around $1030 \mathrm{~cm}^{-}$ 1. Additionally, the new bands formed between $1021 \mathrm{~cm}^{-1}$ and $1037 \mathrm{~cm}^{-1}$ may be ascribed to dimers or oligomers of GA that can result from the stretching vibration of $\mathrm{C}-\mathrm{C}$ and $\mathrm{C}-\mathrm{O}$ bonds. ${ }^{62,63}$ 
In relation to the incorporation of the compatibilizers into the blend, one can observe the development of a shoulder in the carbonyl peak of PA1010 at approximately $1690 \mathrm{~cm}^{-1}$. This chemical change was particularly more intense in the spectrum of the MLO-containing sample and it can be related to the $\mathrm{C}-\mathrm{O}$ stretching group of hydrolyzed anhydride groups due to the reaction of the multiple functional groups of the compatibilizers with the terminal acid groups of PA1010. ${ }^{64}$ However, the symmetric stretching of these newly formed functional groups, expected to appear close to $1350 \mathrm{~cm}^{-1}$, were not explicitly visible to permit verification of this hypothesis due to the proximity of $\mathrm{C}-\mathrm{H}$ band associated with PA1010. In any case, it is clear that the incorporation of both compatibilizers into the blend perturbed the band shape seen at $\sim 1360 \mathrm{~cm}^{-1}$ and the formation of these delocalized carboxyl groups would readily explain this phenomenon. 35

\subsection{Thermal properties}

Figure 3 shows the DSC curves during the second heating of the PA1010/bioHDPE blends containing GA and the different compatibilizers. Table $\mathbf{3}$ gathers some of the most relevant thermal parameters obtained by DSC. Neat PA1010 showed a double melting peak with a low-intense melting point located at $185.2{ }^{\circ} \mathrm{C}$ whereas the main one was nearly at $203{ }^{\circ} \mathrm{C}$. This phenomenon is related to a polymorphism effect on crystallites, showing multiple melting peaks of different intensities due to the presence of different crystalline forms of distinct lamellae and melting profile, that is, $\alpha, \beta$, and $\gamma .65$ One can observe that the addition of $30 \mathrm{wt} \%$ bio-HDPE to the blend did not generate any remarkable changes in the melting process of PA1010. In spite of this, more unstable crystals were present in PA1010/bio-HPPE sample due to the observed decrease in crystallinity. Alternatively, bio-HDPE was characterized by a melting temperature $\left(\mathrm{T}_{\mathrm{m}}\right)$ of $133.4{ }^{\circ} \mathrm{C}$ whereas its onset of degradation temperature was $223.5^{\circ} \mathrm{C}$, which is relatively close to the $\mathrm{T}_{\mathrm{m}}$ of PA1010. It can be observed that the addition of GA did not change in a remarkable way the melting process of both bio- 
HDPE and PA1010, although some PA1010 crystallites melted at lower temperatures. Interestingly, the main effect of GA on the thermal properties of the biopolymer blends was a delay in the onset degradation temperature from $223.5^{\circ} \mathrm{C}$ up to $277.4^{\circ} \mathrm{C}$. This observation implies that the GA addition successfully improved the thermal stability of bio-HDPE, making it much more viable to be processed at higher temperatures without any degradation. Therefore, GA can successfully contribute to widen the processing temperature window of bio-HDPE, fitting these new conditions with the typical processing temperatures of PA1010. In this regard, Samper et al. ${ }^{16}$ reported that the addition of different flavonoids, such as chrysin, quercetin, silibinin A, naringin, and hesperidin, delayed up to $25^{\circ} \mathrm{C}$ the onset degradation process of PP providing, additionally, improved stability to UV radiation. With regard to the crystallinity of PA1010, the presence of the bio-HDPE phase potentially altered the nucleation rate of PA1010 by reducing its crystallinity. ${ }^{46}$ With the addition of the different compatibilizers, some interesting changes in the thermal properties can be observed. While the melting profile of the blends remained almost constant with the addition of both MLO and PE-co-AA, the crystallinity of bio-HDPE increased to $58.6 \%$ and $62.9 \%$ for MLO and PE-co-AA, respectively. Therefore, the presence of MLO and, in particular, PE-co-AA, can favor the formation of more stable bio-HDPE crystals. 35

Regarding the analysis of thermal stability, Figure 4 shows the TGA curves of PA1010/bio-HDPE blends while Table 4 summarizes the main thermal degradation parameters obtained from the TGA curves. One can observe that neat PA1010 showed a relatively high thermal stability, showing a value of $\mathrm{T}_{5 \%}$ (temperature required for a 5 wt\% loss) located at $422{ }^{\circ} \mathrm{C}$, while the maximum degradation rate $\left(\mathrm{T}_{\mathrm{deg}}\right)$ occurred at $461.6^{\circ} \mathrm{C}$. As it can be seen, PA1010 decomposed in a single step with a residual mass of nearly 1.5 wt\%. According to this, Yang et al. ${ }^{66}$ showed similar results for PA1010, observing that the onset thermal degradation was close to $414{ }^{\circ} \mathrm{C}$. Bio-HDPE decomposition occurred at lower temperatures. After the addition of the green polyolefin, the values of $\mathrm{T}_{5 \%}$ and $\mathrm{T}_{\mathrm{deg}}$ of the blend were reduced to $361^{\circ} \mathrm{C}$ and $458{ }^{\circ} \mathrm{C}$, 
respectively. Then, the most relevant change was observed in the $\mathrm{T}_{5 \%}$ value, which was reduced by $60^{\circ} \mathrm{C}$ in comparison with the uncompatibilized and non-stabilized PA1010/bio-HDPE blend, mainly due thermal degradation of bio-HDPE during processing. As it has been described previously, the typical processing temperature for PA1010 overlaps with the initial stages of the thermo-oxidative degradation of bioHDPE, thus leading to a blend with poor thermal stability. The incorporation of GA, interestingly, exerted an antioxidant effect on bio-HDPE, thus enlarging its onset degradation. Therefore, the GA addition provided an enlarged processing window of both polymers without thermal degradation. In particular, the stabilized blend with GA offered a $\mathrm{T}_{5 \%}$ value of $426^{\circ} \mathrm{C}$, slightly higher than neat PA1010, thus exerting a positive effect of GA on the overall thermal stability of the binary blend. ${ }^{67}$

With the addition of MLO, the $\mathrm{T}_{5 \%}$ values were reduced by almost $10{ }^{\circ} \mathrm{C}$ compared to the GA-stabilized PA1010/bio-HDPE blend. This reduction can be related to the plasticizing effect generated by MLO in the blend and the lower thermal stability of the vegetable oil. Similarly, Ferri et al. ${ }^{68}$ previously reported a decrease in the onset degradation temperature of PLA with the addition of bio-based epoxidized fatty acid esters (EFAEs). Regarding the maximum degradation temperature, one can observe that it remained almost constant. The addition of PE-co-AA produced an improvement in the thermal stability of the blend, as it improved both the $\mathrm{T}_{5 \%}$ and $\mathrm{T}_{\text {deg }}$ of PA1010 by more than $5{ }^{\circ} \mathrm{C}$ and $10^{\circ} \mathrm{C}$, respectively. This may be due to the improvement in miscibility between both materials discussed above. In any case, the most favorable result was the thermal stability increase of the blend attained after the incorporation of GA. According to these results, other authors have reported that the onset degradation temperature of bio-HDPE is approximately at $265^{\circ} \mathrm{C}$, ascribed to the start of thermooxidative processes, as corroborated by DSC. The presence of GA enhanced the thermal stability of the PA1010/bio-HDPE blend with a $\mathrm{T}_{5 \%}$ value of up to $420{ }^{\circ} \mathrm{C}$. Finally, in relation to the residual mass, the incorporation of bio-HDPE into the blends slightly reduced the residual mass of PA1010. 


\subsection{Thermomechanical properties}

Figure 5a shows the evolution of the storage modulus (E') of the PA1010/bioHDPE blends in the temperature range comprised between -150 and $100{ }^{\circ} \mathrm{C}$. The incorporation of bio-HDPE into the PA1010 matrix induced a slight increase in E'. In particular, at $-100{ }^{\circ} \mathrm{C}$, it increased from $1300 \mathrm{MPa}$, for neat PA1010, to $1400 \mathrm{MPa}$, for the uncompatibilized and non-stabilized PA1010/bio-HDPE blend. This increase was observed up to temperatures close to $\mathrm{o}^{\circ} \mathrm{C}$. Above this temperature, the stiffness of all materials decreased and it showed similar values at temperatures above $40{ }^{\circ} \mathrm{C}$. The incorporation of GA and, in particular, the combination of GA and MLO, resulted in a slight increase in rigidity. In particular, E' reached a value $1500 \mathrm{MPa}$ at $-100{ }^{\circ} \mathrm{C}$. Other authors have observed a similar behavior in PA1010/bio-HDPE blends compatibilized with MLO by reactive extrusion with dicumyl peroxide (DCP).50 In the case of PE-coAA, one can observe that it did not provide any significant change in the E' values.

Figure 5b shows the evolution of the dynamic damping factor $(\tan \delta$ ) with temperature of PA1010 and the PA1010/bio-HDPE blends. Regarding the neat PA1010, the typical relaxations are in total accordance to those reported by other authors. As indicated by Pagacz et al. ${ }^{69}$, the peak around $-130{ }^{\circ} \mathrm{C}$ is related to the $\gamma$-relaxation, which has been attributed to motions of methylene groups. ${ }^{\circ 0}$ The peak located at around $-80{ }^{\circ} \mathrm{C}$ corresponds to the $\beta$-relaxation, which is typically attributed to nonhydrogen-bonded amide group and, in some cases, to water molecules bonded on carbonyl groups..$^{\circ}$ Finally, the peak with the highest intensity, at nearly $50^{\circ} \mathrm{C}$, is attributed to the $\alpha$-relaxation or glass transition temperature $\left(\mathrm{T}_{\mathrm{g}}\right)$ of PA1010. ${ }^{71}{ }^{72}$ With regard to the $\mathrm{T}_{\mathrm{g}}$ of PA1010, the incorporation of MLO increased the $\mathrm{T}_{\mathrm{g}}$ value from $54{ }^{\circ} \mathrm{C}$ to $59^{\circ} \mathrm{C}$. A similar behavior has been observed for MLO in different polymer systems. In particular, due to the molecular structure of MLO, different processes could occur simultaneously, that is, plasticization, chain extension, branching, compatibilization, cross-linking, etc. Therefore, despite the fact that the plasticizing effect was evident 
during the mechanical analysis, some cross-linking and compatibilization could also occur with a subsequent increase in $\mathrm{T}_{\mathrm{g}}$. Alternatively, the addition of PE-co-AA did not imply a remarkable change in $\mathrm{T}_{\mathrm{g}}$ of PA1010. In accordance to this, Halldén et al.73 reported that the addition of poly(ethylene-graft-ethylene oxide) (PE-g-PEO) did not produced any relevant change in the Tg of LDPE/PA6 blends.

The peak located between $-112{ }^{\circ} \mathrm{C}$ and $-116{ }^{\circ} \mathrm{C}$ corresponds to the $\alpha$-relaxation of bio-HDPE, which is also related to its $\mathrm{T}_{\mathrm{g}}$. One can observe that this second order transition temperature overlapped with the $\gamma$-relaxation process of PA1010. However, a slight increase of $3^{\circ} \mathrm{C}$ was observed in the PA1010/bio-HDPE blend stabilized with GA and also compatibilized with MLO, which is in accordance to the above-mentioned potential effects of the multi-functionalized vegetable oil on the polymer blends. Indeed, $\mathrm{T}_{\mathrm{g}}$ is a clear indicator of the level of miscibility in a polymer blend. Briefly, thermodynamically immiscible blends show different clearly distinguishable $\mathrm{T}_{\mathrm{g}}$ values whereas in partially miscible blends a shift on $\mathrm{T}_{\mathrm{g}}$ from the value of one component towards the other is typically attained and fully miscible blends are characterized by a single $\mathrm{T}_{\mathrm{g}} \cdot{ }^{74}$

In addition to the thermomechanical characterization carried out by DMTA, the dimensional stability was evaluated by thermomechanical analysis (TMA). In particular, the coefficient of linear thermal expansion (CLTE) was studied and the most relevant parameters are summarized in Table 5. The CLTE values were measured below and above the $\mathrm{T}_{\mathrm{g}}$ of PA1010. At temperatures below the $\mathrm{T}_{\mathrm{g}}$ of PA1010, a slight increase in the CLTE values was seen for the uncompatibilized and non-stabilized PA1010/bio-HDPE blend. The incorporation of GA and the different compatibilizers, that is, MLO and PE-co-AA, did not provide any remarkable change in the CLTE values below the $T_{g}$ of PA1010. As opposite, above the $T_{g}$ of PA1010, changes in CLTE were much more noticeable. The addition of $30 \mathrm{wt} \%$ bio-HDPE resulted in an increase of more than $350 \mu \mathrm{m} / \mathrm{m}^{\circ} \mathrm{C}$. This effect is mainly due to the large CLTE of bio-HDPE above $70{ }^{\circ} \mathrm{C}$, which is around $465 \mu \mathrm{m} / \mathrm{m}{ }^{\circ} \mathrm{C}$ as reported previously..$^{\circ}$ The only addition 
of GA provided slightly lower values, but with both compatibilizers, the CLTE increased in accordance to the above-reported results of elongation at break. In particular, it is worthy to note the high CLTE value observed for the blend compatibilized with PE-coAA, which was $689 \mu \mathrm{m} / \mathrm{m}{ }^{\circ} \mathrm{C}$. This increase may be related to the plasticizing effect that both compatibilizers can provide to the blend, being particularly more intense in the case of PE-co-AA, as it was described in mechanical properties of the biopolymer blends. This increase in CLTE with the addition of MLO has been observed previously in PLA/ASF composites.35 Moreover, the plasticization was much more pronounced at higher temperatures.

\section{CONCLUSIONS}

This work shows the effectiveness of GA as a natural antioxidant in PA1010/bioHDPE, both biopolymers being fully obtained from renewable resources but also highly immiscible as observed by FESEM. GA successfully enlarged the processing temperature window of the blend by increasing the thermal stability of bio-HDPE, thus allowing its better processability with PA1010. In addition, GA provided a clear plasticizing effect on the biopolymer blend, which resulted in a positive effect on the ductility of the PA1010/bio-HDPE blends. This binary blend, containing 70 wt\% PA1010 and 30 wt\% bio-HDPE, showed a droplet-like surface morphology with spherical bio-HDPE particles sizing $5^{-15} \mu \mathrm{m}$ embedded in the PA1010 matrix. In addition to the improvement observed in the thermal stability by the addition GA, the two tested reactive compatibilizers showed a high efficiency to also provide partial compatibilization with a subsequent improvement in toughness. Addition of MLO provided certain plasticization and improved impact strength, whereas the addition of the petroleum-derived PE-co-AA compatibilizer induced improved elongation at break and tensile strength. This was representative for somewhat compatibilization, as corroborated by FESEM due to the size of the spherical bio-HDPE domains decreased 
to values lower than $5 \mu \mathrm{m}$ and also by the chemical interactions described during FTIR analysis.

The results of this research work also overcome the main drawbacks related to the mechanical recycling of these two biopolymers. One the one hand, the processing temperature of the binary blend is improved by using GA. On the other, MLO compatibilizes both biopolymers resulting in a blend with improved toughness. Therefore, this approach could positively contribute to the development of highperformance blends based on immiscible biopolymers and also to the promotion of sustainable polymer technologies.

\section{Acknowledgements}

This research was funded by the Spanish Ministry of Science, Innovation, and Universities (MICIU) project numbers MAT2017-84909-C2-2-R and AGL2015-63855C2-1-R. Quiles-Carrillo and Torres-Giner are recipients of a FPU grant (FPU15/o3812) from the Spanish Ministry of Education, Culture, and Sports (MECD) and a Juan de la Cierva-Incorporación contract (IJCI-2016-29675) from MICIU, respectively. The microscopy services at Universitat Politècnica de València (UPV) are acknowledged for their help in collecting and analyzing FESEM images. 


\section{References}

1 T. M. Carole, J. Pellegrino and M. D. Paster, Opportunities in the industrial biobased products industry, in Proceedings of the Twenty-Fifth Symposium on Biotechnology for Fuels and Chemicals Held May 4-7, 2003, in Breckenridge, CO. Springer, pp. 871-885 (2004).

2 D. S. Ogunniyi, Bioresource technology 97:1086-1091 (2006).

3 A. Kausar, Advances in Materials Science 17:24-36 (2017).

$4 \quad$ Y. Nishitani, T. Kajiyama and T. Yamanaka, Materials 10:1040 (2017).

5 D. Glasscock, W. Atolino, G. Kozielski and M. Martens, DuPont Engineering Polymers (2008).

$6 \quad$ R. Boros, P. Rajamani and J. Kovács, Materials 11:2140 (2018).

7 M. Del Nobile, G. Buonocore, L. Palmieri, A. Aldi and D. Acierno, Journal of food engineering 53:287-293 (2002).

$8 \quad$ H. Nishida, Polymer journal 43:435 (2011).

9 R. Singh, R. Kumar, N. Ranjan, R. Penna and F. Fraternali, Composite Structures 184:704-713 (2018).

10 R. Laryea-Goldsmith, J. Oakey and N. J. Simms, Chemistry Central Journal 5:4 (2011).

11 S. Kumar, A. K. Panda and R. Singh, Resources, Conservation and Recycling 55:893-910 (2011).

12 J. Araújo, W. Waldman and M. De Paoli, Polymer Degradation and stability 93:17701775 (2008).

13 L. Sangroniz, M. A. Moncerrate, V. A. De Amicis, J. K. Palacios, M. Fernández, A. Santamaria, J. J. Sánchez, F. Laoutid, P. Dubois and A. J. Müller, Journal of Polymer Science Part B: Polymer Physics 53:1567-1579 (2015).

14 M. Sahnoune, A. Taguet, B. Otazaghine, M. Kaci and J. M. Lopez-Cuesta, Polymer International 66:300-312 (2017).

15 M.-Y. Lim, J. Oh, H. J. Kim, K. Y. Kim, S.-S. Lee and J.-C. Lee, European Polymer Journal 69:156-167 (2015).

16 M. Samper, E. Fages, O. Fenollar, T. Boronat and R. Balart, Journal of Applied Polymer Science 129:1707-1716 (2013).

17 M. A. Raspo, C. G. Gomez and A. E. Andreatta, Polymer Testing 70:180-187 (2018).

18 H. N. Graham, Preventive medicine 21:334-350 (1992).

19 Y. Yilmaz and R. T. Toledo, Journal of agricultural and food chemistry 52:255-260 (2004).

20 J. Vourdoubas and V. K. Skoulou, Studies in Engineering and Technology 4:25-34 (2017).

21 L. Quiles-Carrillo, C. Mellinas, M. Garrigos, R. Balart and S. Torres-Giner, Food Analytical Methods 1-11 (2019).

22 C. Macosko, P. Guegan, A. K. Khandpur, A. Nakayama, P. Marechal and T. Inoue, Macromolecules 29:5590-5598 (1996).

23 A. Kumar, T. V. Rao, S. R. Chowdhury and S. Reddy, Effect of electron beam irradiation on thermal and mechanical properties of poly (lactic acid)/poly (ethylene-co-glycidyl methacrylate) blend, in AIP Conference Proceedings. AIP Publishing, pp. 020039 (2017).

24 A. Arostegui and J. Nazabal, Journal of Polymer Science Part B: Polymer Physics 41:2236-2247 (2003).

25 J. Sheng, H. Ma, X. B. Yuan, X. Y. Yuan, N. X. Shen and D. C. Bian, Journal of applied polymer science 76:488-494 (2000). 

International 65:1157-1164 (2016).

27 M. A. Mosiewicki and M. I. Aranguren, Polymer International 65:28-38 (2016).

28 L. Quiles-Carrillo, S. Duart, N. Montanes, S. Torres-Giner and R. Balart, Materials \& Design 140:54-63 (2018).

29 A. Carbonell-Verdu, D. Garcia-Garcia, F. Dominici, L. Torre, L. Sanchez-Nacher and R. Balart, European Polymer Journal 91:248-259 (2017).

30 K. Liu, S. A. Madbouly and M. R. Kessler, European Polymer Journal 69:16-28 (2015).

31 L. Quiles-Carrillo, M. Blanes-Martínez, N. Montanes, O. Fenollar, S. Torres-Giner and R. Balart, European Polymer Journal 98:402-410 (2018).

32 M. J. Garcia-Campo, L. Quiles-Carrillo, J. Masia, M. J. Reig-Pérez, N. Montanes and R. Balart, Materials 10:1339 (2017).

33 J. Ferri, D. Garcia-Garcia, L. Sánchez-Nacher, O. Fenollar and R. Balart, Carbohydrate polymers 147:60-68 (2016).

34 J. M. Ferri, D. Garcia-Garcia, N. Montanes, O. Fenollar and R. Balart, Polymer International 66:882-891 (2017).

35 L. Quiles-Carrillo, N. Montanes, C. Sammon, R. Balart and S. Torres-Giner, Industrial Crops and Products 111:878-888 (2018).

36 S. Miao, P. Wang, Z. Su and S. Zhang, Acta Biomaterialia 10:1692-1704 (2014).

37 A. Aguero, L. Quiles-Carrillo, A. Jorda-Vilaplana, O. Fenollar and N. Montanes, Polymer International 68:893-903 (2019).

38 M. Yan and H. Yang, Polymer Composites 33:1770-1776 (2012).

39 L. Quiles-Carrillo, N. Montanes, J. Lagaron, R. Balart and S. Torres-Giner, Journal of Polymers and the Environment 27:84-96 (2019).

40 R. Scaffaro, M. C. Mistretta, F. P. La Mantia, M. Gleria, R. Bertani, F. Samperi and C. Puglisi, Macromolecular Chemistry and Physics 207:1986-1997 (2006).

41 J. Wu, S. Chen, S. Ge, J. Miao, J. Li and Q. Zhang, Food Hydrocolloids 32:42-51 (2013).

42 V. Ambrogi, P. Cerruti, C. Carfagna, M. Malinconico, V. Marturano, M. Perrotti and P. Persico, Polymer degradation and stability 96:2152-2158 (2011).

43 M. Jamshidian, E. A. Tehrany, M. Imran, M. J. Akhtar, F. Cleymand and S. Desobry, Journal of Food Engineering 110:380-389 (2012).

44 J. M. Ferri, D. Garcia-Garcia, L. Sanchez-Nacher, O. Fenollar and R. Balart, Carbohydrate Polymers 147:60-68 (2016).

45 P. Liminana, D. Garcia-Sanoguera, L. Quiles-Carrillo, R. Balart and N. Montanes, Composites Part B-Engineering 144:153-162 (2018).

46 Å. Halldén, B. Ohlsson and B. Wesslén, Journal of applied polymer science 78:24162424 (2000).

47 J. Balart, V. Fombuena, O. Fenollar, T. Boronat and L. Sánchez-Nacher, Composites Part B: Engineering 86:168-177 (2016).

48 M. Mistretta, P. Fontana, M. Ceraulo, M. Morreale and F. La Mantia, Polymer Degradation and Stability 112:192-197 (2015).

49 L. A. Utracki, The Canadian Journal of Chemical Engineering 80:1008-1016 (2002).

50 L. Quiles-Carrillo, N. Montanes, A. Jorda-Vilaplana, R. Balart and S. Torres-Giner, Journal of Applied Polymer Science 136:47396 (2019).

51 A. Carbonell-Verdu, D. Garcia-Sanoguera, A. Jordá-Vilaplana, L. Sanchez-Nacher and R. Balart, Journal of Applied Polymer Science 133:(2016).

52 Z. S. Petrović, M. lonescu, J. Milić and J. R. Halladay, Rubber chemistry and technology 86:233-249 (2013).

53 M. Garcia-Campo, L. Quiles-Carrillo, J. Masia, M. Reig-Pérez, N. Montanes and R. Balart, Materials 10:1339 (2017).

54 Q. Wang, R. Qi, Y. Shen, Q. Liu and C. Zhou, Journal of applied polymer science 106:3220-3226 (2007). 
55 H. P. Li and Z. M. Li, Polymer International 48:124-128 (1999).

56 M. Porubska, O. Szoellos, A. Konova, I. Janigova, M. Jaskova, K. Jomova and I. Chodak, Polymer Degradation and Stability 97:523-531 (2012).

57 F.-C. Pai, S.-M. Lai and H.-H. Chu, Journal of Applied Polymer Science 130:2563-2571 (2013).

58 T. Elzein, M. Brogly and J. Schultz, Polymer 43:4811-4822 (2002).

59 S. Rhee and J. L. White, Polymer Engineering and Science 42:134-145 (2002).

60 N. Vasanthan and D. R. Salem, Journal of Polymer Science Part B-Polymer Physics 39:536-547 (2001).

61 L. Barbeş, C. Rădulescu and C. Stihi, Romanian Reports in Physics 66:765-777 (2014).

62 Y. P. Neo, S. Ray, J. Jin, M. Gizdavic-Nikolaidis, M. K. Nieuwoudt, D. Liu and S. Y. Quek, Food chemistry 136:1013-1021 (2013).

63 S. A. Markarian, A. L. Zatikyan, S. Bonora and C. Fagnano, Journal of molecular structure 655:285-292 (2003).

64 C. H. Wu and A. C. Su, Polymer Engineering and Science 31:1629-1636 (1991).

65 E. Logakis, C. Pandis, V. Peoglos, P. Pissis, C. Stergiou, J. Pionteck, P. Pötschke, M. Mičušík and M. Omastová, Journal of Polymer Science Part B: Polymer Physics 47:764774 (2009).

66 J. Yang, W. Dong, Y. Luan, J. Liu, S. Liu, X. Guo, X. Zhao and W. Su, Journal of applied polymer science 83:2522-2527 (2002).

67 W. Pasanphan, G. R. Buettner and S. Chirachanchai, Journal of applied polymer science 109:38-46 (2008).

68 J. Ferri, M. Samper, D. García-Sanoguera, M. Reig, O. Fenollar and R. Balart, Journal of materials science 51:5356-5366 (2016).

69 J. Pagacz, K. N. Raftopoulos, A. Leszczyńska and K. Pielichowski, Journal of Thermal Analysis and Calorimetry 123:1225-1237 (2016).

70 D. Prevorsek, R. Butler and H. Reimschuessel, Journal of Polymer Science Part A-2: Polymer Physics 9:867-886 (1971).

71 C. Zhao, G. Hu, R. Justice, D. W. Schaefer, S. Zhang, M. Yang and C. C. Han, Polymer 46:5125-5132 (2005).

72 K. Urman and J. Otaigbe, Journal of Polymer Science Part B: Polymer Physics 44:441450 (2006).

73 Å. Halldén, M. J. Deriss and B. Wesslén, Polymer 42:8743-8751 (2001).

74 R. Muthuraj, M. Misra and A. K. Mohanty, Journal of Applied Polymer Science 134:45448 (2017). 


\section{Tables}

Table 1. Summary of compositions according to the weight content (wt\%) of polyamide 1010 (PA1010) and bio-based high-density polyethylene (bio-HDPE) blends in which gallic acid (GA), maleinized linseed oil (MLO), and poly(ethylene-co-acrylic acid) copolymer (PE-co-AA) were added as parts per hundred resin (phr) of biopolymer blend.

\begin{tabular}{|l|c|c|c|c|c|}
\hline Code & $\begin{array}{c}\text { PA1010 } \\
\mathbf{( w t \% )}\end{array}$ & $\begin{array}{c}\text { Bio- } \\
\text { HDPE } \\
(\mathbf{w t} \%)\end{array}$ & $\begin{array}{c}\text { GA } \\
\text { (phr) }\end{array}$ & $\begin{array}{c}\text { MLO } \\
\text { (phr) }\end{array}$ & $\begin{array}{c}\text { PE-co-AA } \\
\text { (phr) }\end{array}$ \\
\hline PA1010 & 100 & 0 & 0 & 0 & 0 \\
\hline PA1010/bio-HDPE & 70 & 30 & 0 & 0 & 0 \\
\hline PA1010/bio-HDPE /GA & 70 & 30 & 0.8 & 0 & 0 \\
\hline PA1010/bio-HDPE/GA/MLO & 70 & 30 & 0.8 & 5 & 0 \\
\hline PA1010/bio-HDPE/GA/PE-co-AA & 70 & 30 & 0.8 & 0 & 5 \\
\hline
\end{tabular}


Table 2. Summary of the mechanical properties of polyamide 1010 (PA1010)/biobased high-density polyethylene (bio-HDPE) blends processed with gallic acid (GA), maleinized linseed oil (MLO), and poly(ethylene-co-acrylic acid) copolymer (PE-co-AA) in terms of: tensile modulus $(\mathrm{E})$, maximum tensile strength $\left(\sigma_{\max }\right)$, elongation at break $\left(\varepsilon_{\mathrm{b}}\right)$, Shore D hardness, and impact strength.

\begin{tabular}{|c|c|c|c|c|c|}
\hline Sample & E (MPa) & $\begin{array}{c}\sigma_{\max } \\
(\mathbf{M P a})\end{array}$ & $\varepsilon_{b}(\%)$ & $\begin{array}{l}\text { Shore D } \\
\text { hardness }\end{array}$ & $\begin{array}{l}\text { Impact } \\
\text { strength } \\
\left(\mathrm{kJ} / \mathrm{m}^{2}\right)\end{array}$ \\
\hline PA1010 & $639.2 \pm 24$ & $48.6 \pm 1.5$ & $515.8 \pm 16.8$ & $73.4 \pm 0.8$ & $8.3 \pm 0.6$ \\
\hline Bio-HDPE & $364.6 \pm 18$ & $19.4 \pm 0.8$ & $518.2 \pm 22.3$ & $59.6 \pm 0.9$ & $3.5 \pm 0.2$ \\
\hline PA1010/bio-HDPE & $298.3 \pm 29$ & $26.9 \pm 1.9$ & $72.8 \pm 14.6$ & $70.0 \pm 1.0$ & $2.8 \pm 0.2$ \\
\hline PA1010/bio-HDPE /GA & $266.0 \pm 23$ & $26.1 \pm 0.5$ & $134.3 \pm 11.7$ & $70.2 \pm 1.1$ & $3.7 \pm 0.6$ \\
\hline PA1010/bio-HDPE/GA/MLO & $237.5 \pm 12$ & $23.3 \pm 0.6$ & $139.6 \pm 9.1$ & $67.8 \pm 0.7$ & $4.3 \pm 0.5$ \\
\hline $\begin{array}{l}\text { PA1010/bio-HDPE/GA/PE- } \\
\text { co-AA }\end{array}$ & $240.1 \pm 19$ & $30.6 \pm 0.4$ & $150.8 \pm 14.8$ & $70.6 \pm 0.9$ & $3.5 \pm 0.2$ \\
\hline
\end{tabular}


Table 3. Main thermal parameters of polyamide 1010 (PA1010)/bio-based highdensity polyethylene (bio-HDPE) blends processed with gallic acid (GA), maleinized linseed oil (MLO), and poly(ethylene-co-acrylic acid) copolymer (PEco-AA) in terms of: melting temperature $\left(\mathrm{T}_{\mathrm{m}}\right)$, normalized enthalpy of melting $\left(\Delta \mathrm{H}_{\mathrm{m}}\right)$, and degree of crystallinity $\left(\mathrm{X}_{\mathrm{C}}\right)$ for the PA1010 and bio-HDPE phases and degradation temperature $\left(\mathrm{T}_{\mathrm{deg}}\right)$ of bio-HDPE.

\begin{tabular}{|c|c|c|c|c|c|c|c|}
\hline Sample & $\begin{array}{l}\mathbf{T}_{\mathrm{m}}\left({ }^{\circ} \mathrm{C}\right) \\
\text { PA1010 }\end{array}$ & $\begin{array}{c}\Delta \mathbf{H}_{\mathrm{m}} \\
\left(\mathrm{J} \mathrm{g}^{-1}\right) \\
\text { PA1010 }\end{array}$ & $\begin{array}{c}\chi_{\mathrm{c}}(\%) \\
\text { PA1010 }\end{array}$ & $\begin{array}{c}\mathrm{T}_{\mathrm{m}}\left({ }^{\circ} \mathrm{C}\right) \\
\text { Bio- } \\
\text { HDPE }\end{array}$ & $\begin{array}{l}\Delta H_{\mathrm{m}}\left(\mathrm{J} \mathrm{g}^{-1}\right) \\
\text { Bio-HDPE }\end{array}$ & $\begin{array}{c}\chi_{\mathrm{c}}(\%) \\
\text { Bio- } \\
\text { HDPE }\end{array}$ & $\begin{array}{r}\mathbf{T}_{\mathrm{deg}}\left({ }^{\circ} \mathrm{C}\right) \\
\text { Bio-HDPE }\end{array}$ \\
\hline PA1010 & $\begin{array}{c}185.2 / 203.5 \\
\pm 1.1\end{array}$ & $\begin{array}{c}86.6 \pm \\
1.2\end{array}$ & $35.5 \pm 1.1$ & - & - & - & - \\
\hline Bio-HDPE & - & - & - & $133.1 \pm 0.6$ & $159.3 \pm 0.8$ & $54.4 \pm 0.7$ & $224.9 \pm 0.8$ \\
\hline $\begin{array}{l}\text { PA1010/bio- } \\
\text { HDPE }\end{array}$ & $\begin{array}{c}183.2 / 203.8 \\
\pm 1.3\end{array}$ & $\begin{array}{c}42.6 \pm \\
1.1\end{array}$ & $24.9 \pm 1.1$ & $\begin{array}{c}133.4 \pm \\
0.7\end{array}$ & $45 \cdot 3 \pm 0.8$ & $51.5 \pm 0.7$ & $223.5 \pm 0.7$ \\
\hline $\begin{array}{l}\text { PA1010/bio- } \\
\text { HDPE /GA }\end{array}$ & $\begin{array}{c}184.5 / 205.2 \\
\pm 0.9\end{array}$ & $\begin{array}{c}43.1 \pm \\
0.8\end{array}$ & $25.2 \pm 0.8$ & $\begin{array}{c}135.5 \pm \\
0.8\end{array}$ & $41.2 \pm 0.6$ & $46.9 \pm 0.6$ & $277.4 \pm 0.9$ \\
\hline $\begin{array}{l}\text { PA1010/bio- } \\
\text { HDPE/GA/ } \\
\text { MLO }\end{array}$ & $\begin{array}{c}183.3 / 203.8 \\
\pm 1.2\end{array}$ & $\begin{array}{c}42.2 \pm \\
1.0\end{array}$ & $24.7 \pm 1.0$ & $133.1 \pm 0.4$ & $51.5 \pm 0.9$ & $58.6 \pm 0.9$ & $275.5 \pm 0.7$ \\
\hline $\begin{array}{l}\text { PA1010/bio- } \\
\text { HDPE/GA/P } \\
\text { E-co-AA }\end{array}$ & $\begin{array}{c}183.4 / 203.7 \\
\pm 1.1\end{array}$ & $\begin{array}{c}40.2 \pm \\
1.2\end{array}$ & $23.5 \pm 1.1$ & $\begin{array}{c}133.5 \pm \\
0.6\end{array}$ & $55.3 \pm 0.5$ & $62.9 \pm 0.5$ & $275.2 \pm 0.8$ \\
\hline
\end{tabular}


Table 4. Main thermal degradation parameters of polyamide 1010 (PA1010)/biobased high-density polyethylene (bio-HDPE) blends processed with gallic acid (GA), maleinized linseed oil (MLO), and poly(ethylene-co-acrylic acid) copolymer (PE-co-AA) in terms of: onset temperature for a mass loss of $5 \%\left(\mathrm{~T}_{5 \%}\right)$, temperature for a mass loss of $10 \%\left(\mathrm{~T}_{10 \%}\right)$, degradation temperature $\left(\mathrm{T}_{\mathrm{deg}}\right)$, temperature for a mass loss of $90 \%\left(\mathrm{~T}_{90 \%}\right)$, and residual mass at $700{ }^{\circ} \mathrm{C}$.

\begin{tabular}{|l|c|c|c|c|l|}
\hline Sample & $\mathbf{T}_{5 \%}\left({ }^{\circ} \mathbf{C}\right)$ & $\mathbf{T}_{10 \%}\left({ }^{\circ} \mathbf{C}\right)$ & $\mathbf{T}_{\text {deg }}\left({ }^{\circ} \mathbf{C}\right)$ & $\mathbf{T}_{\mathbf{9 0} \%}\left({ }^{\circ} \mathbf{C}\right)$ & $\begin{array}{l}\text { Residual } \\
\text { mass } \\
\mathbf{( \% )}\end{array}$ \\
\hline PA1010 & $422.0 \pm 0.8$ & $431.3 \pm 0.8$ & $461.6 \pm 1.0$ & $511.6 \pm 0.9$ & $1.5 \pm 0.2$ \\
\hline Bio-HDPE & $304.2 . \pm 0.8$ & $331.0 \pm 0.9$ & $429.7 \pm 0.8$ & $480.2 \pm 0.8$ & $0.3 \pm 0.1$ \\
\hline PA1010/bio-HDPE & $361.0 \pm 0.9$ & $424.2 \pm 0.7$ & $458.2 \pm 1.1$ & $492.4 \pm 0.8$ & $0.6 \pm 0.1$ \\
\hline $\begin{array}{l}\text { PA1010/bio-HDPE } \\
\text { /GA }\end{array}$ & $426.0 \pm 1.8$ & $433.1 \pm 0.8$ & $457.8 \pm 0.9$ & $493.2 \pm 0.7$ & $1.2 \pm 0.2$ \\
\hline $\begin{array}{l}\text { PA1010/bio- } \\
\text { HDPE/GA/MLO }\end{array}$ & $417.5 \pm 1.2$ & $429.3 \pm 0.9$ & $460.1 \pm 0.8$ & $494.3 \pm 0.8$ & $1.4 \pm 0.3$ \\
\hline $\begin{array}{l}\text { PA1010/bio- } \\
\text { HDPE/GA/PE-co- } \\
\text { AA }\end{array}$ & $431.0 \pm 1.3$ & $443.4 \pm 0.7$ & $469.5 \pm 0.9$ & $496.1 \pm 1.0$ & $1.1 \pm 0.2$ \\
\hline
\end{tabular}


Table 5. Values of the coefficients of linear thermal expansion (CLTE) of polyamide 1010 (PA1010)/bio-based high-density polyethylene (bio-HDPE) blends processed with gallic acid (GA), maleinized linseed oil (MLO), and poly(ethylene-co-acrylic acid) copolymer (PE-co-AA) below and above the glass transition temperature $\left(\mathrm{T}_{\mathrm{g}}\right)$ of PA1010.

\begin{tabular}{|l|c|c|}
\hline \multirow{2}{*}{ Sample } & \multicolumn{2}{|c|}{ CLTE $\left(\mu \mathrm{m} / \mathrm{m}^{\circ} \mathrm{C}\right)$} \\
\cline { 2 - 3 } & Below $\mathbf{T}_{\mathbf{g}}$ & Above T$_{\mathbf{g}}$ \\
\hline PA1010 & $97.2 \pm 1.9$ & $206.0 \pm 2.6$ \\
\hline PA1010/bio-HDPE & $107.2 \pm 2.0$ & $559.2 \pm 3.8$ \\
\hline PA1010/bio-HDPE /GA & $104.0 \pm 1.5$ & $422.9 \pm 2.9$ \\
\hline PA1010/bio-HDPE/GA/MLO & $105.9 \pm 2.2$ & $585.6 \pm 3.1$ \\
\hline PA1010/bio-HDPE/GA/PE-co-AA & $111.3 \pm 1.9$ & $689.4 \pm 7.6$ \\
\hline
\end{tabular}




\section{Figure legends}

Scheme 1. Schematic representation of the chemical structure of the base polymers polyamide 1010 (PA1010) and bio-based high-density polyethylene (bio-HDPE) and the additives gallic acid (GA), maleinized linseed oil (MLO), and poly(ethylene-co-acrylic acid) copolymer (PE-co-AA).

Figure 1. Field emission scanning electron microscopy (FESEM) images of fractured surfaces from impacts tests, taken at 500x and 2500x (left and right, respectively) corresponding to polyamide 1010 (PA1010)/bio-based high-density polyethylene (bioHDPE) blends processed with gallic acid (GA), maleinized linseed oil (MLO), and poly(ethylene-co-acrylic acid) copolymer (PE-co-AA): a, b) PA1010; c, d) PA1010/bioHDPE; e, f) PA1010/bio-HDPE/GA; g, h) PA1010/bio-HDPE/MLO ; i, j) PA1010/bioHDPE/GA/PE-co-AA.

Figure 2. Fourier transform infrared (FTIR) spectra, from bottom to top, of polyamide 1010 (PA1010), PA1010/ bio-based high-density polyethylene (bio-HDPE), PA1010/bio-HDPE/gallic acid (GA), PA1010/bio-HDPE/ maleinized linseed oil (MLO), and PA1010/bio-HDPE/GA/poly(ethylene-co-acrylic acid) copolymer (PE-co-AA).

Figure 3. Differential scanning calorimetry (DSC) curves corresponding to polyamide 1010 (PA1010)/bio-based high-density polyethylene (bio-HDPE) blends processed with gallic acid (GA), maleinized linseed oil (MLO), and poly(ethylene-co-acrylic acid) copolymer (PE-co-AA).

Figure 4. Thermogravimetric analysis (TGA) curves corresponding to polyamide 1010 (PA1010)/bio-based high-density polyethylene (bio-HDPE) blends processed with gallic acid (GA), maleinized linseed oil (MLO), and poly(ethylene-co-acrylic acid) copolymer (PE-co-AA).

Figure 5. Dynamic mechanical thermal analysis (DMTA) of polyamide 1010 (PA1010)/bio-based high-density polyethylene (bio-HDPE) blends processed with gallic acid (GA), maleinized linseed oil (MLO), and poly(ethylene-co-acrylic acid) copolymer (PE-co-AA): a) storage modulus (E') and b) dynamic damping factor (tan $\delta$ ). 